\title{
Pressure injury risk assessment in intensive care units: Comparison of the reliability and predictive validity of the Braden and Jackson/Cubbin scales
}

\author{
Seyma Adibelli RN, MSN, Research Assistant (D) | Fatos Korkmaz RN, PhD, Associate \\ Professor
}

Hacettepe University Faculty of Nursing, Ankara, Turkey

\section{Correspondence}

Seyma Adibelli, Hacettepe University Faculty of Nursing, 06100-Ankara, Turkey. Email: symadibelli@gmail.com

\begin{abstract}
Aims and objectives: To compare the reliability and predictive validity of the Braden and Jackson/Cubbin PI risk assessment scales in intensive care unit patients.

Background: Risk assessment with a standardised tool is the usual intervention for preventing pressure injury. Therefore, tools used to assess pressure injury risk should be valid and reliable for the designated patient population.

Design: A prospective and cross-sectional study adheres to the STARD guideline.

Methods: This study was conducted between November 2017-April 2018 in the intensive care units of a tertiary level university hospital in Turkey. The study sample consisted of 176 patients admitted to three intensive care units. Risk assessment was performed once daily with the Braden scale, followed immediately with the Jackson/ Cubbin scale. Risk assessment was terminated on the day of pressure injury development or upon patient discharge from the intensive care unit. Each patient's final risk assessment was considered in the data analysis.

Results: The Cronbach's alpha coefficient of the Jackson/Cubbin and Braden scales was .78 and .85 , respectively. The predictive validity of the Jackson/Cubbin scale was confirmed by a sensitivity of .87 , specificity of .84 , positive predictive value of .47 and negative predictive value of .97 . These values for the Braden scale were $.95, .75, .38$ and .99 , respectively.
\end{abstract} Check for
updates 


\section{1 | INTRODUCTION}

Pressure injuries (PIs) are a largely preventable healthcare problem in all areas of health care. Intensive care units (ICUs) are one of the care settings with a high incidence of Pls, with a prevalence ranging from 14\%-33.7\% (Coyer et al., 2017; El-Marsi, Zein-El-Dine, Zein, Doumit, \& Badr, 2018; Mehta, George, Mehta, \& Wangmo, 2015). By contrast, the prevalence of Pls is $7.8 \%-13.5 \%$ in all clinical settings (Mehta et al., 2015; VanGilder, Lachenbruch, Algrim-Boyle, \& Meyer, 2017) and from 3\%-18.5\% in acute care settings (Coyer et al., 2017; Tubaishat, Papanikolaou, Anthony, \& Habiballah, 2018; Whittington \& Briones, 2004). Similarly, the PI incidence of $13.6 \%-20.1 \%$ in ICUs (Becker et al., 2017; Manzano et al., 2010; Nijs et al., 2009) is almost three times greater than that observed in acute care settings (5.4\%-9\%) (Jenkins \& O'Neal, 2010; Whittington \& Briones, 2004).

The main reasons for the higher prevalence and incidence of Pls in ICUs are patient-related factors, which can include advanced age, limited activity and mobility, level of consciousness, changes in perfusion parameters and nutritional status, presence of comorbidities (such as diabetes mellitus [DM], chronic heart failure [CHF], chronic obstructive pulmonary disease [COPD] and chronic renal failure [CRF]), faecal incontinence, medications (e.g. use of vasopressors, sedatives and steroids), and low haemoglobin and plasma protein levels (Alderden, Rondinelli, Pepper, Cummins, \& Whitney, 2017; Bly, Schallom, Sona, \& Klinkenberg, 2016; Cox, 2017; de Almeida Medeiros et al., 2018; González-Méndez, Lima-Serrano, MartínCastaño, Alonso-Araujo, \& Lima-Rodríguez, 2018). Consequently, a valid and reliable scale that includes these factors is essential for assessing a patient's PI risk and determining the necessary preventive interventions (Australian Wound Management Association, 2012; Haesler, National Pressure Ulcer Advisory Panel, European Pressure Ulcer Advisory Panel, \& Pan Pacific Pressure Injury Alliance, 2014; National Pressure Ulcer Advisory Panel, 2016).

\section{1 | Background}

In the ICU, the most commonly used PI risk assessment tool is the Braden scale (Balzer, Pohl, Dassen, \& Halfens, 2007; Kılıç Fırat \& Sucudağ, 2017; Magnan \& Maklebust, 2009; Seongsook, Ihnsook, $\&$ Younghee, 2004). This scale was developed for use in the general population and consists of the following categories: sensory perception, moisture, activity, mobility, nutrition, friction and shear (Bergstrom, Braden, Laguzza, \& Holman, 1987). Therefore, the Braden scale assesses the main risk factors, but not all risk factors, that may cause PIs in ICU patients. However, the available literature provides evidence that both supports and opposes this interpretation. For example, García-Fernández, PancorboHidalgo, and Agreda (2013), who conducted a systematic review and meta-analysis on PI risk assessment scales in ICU patients, reported that the Braden scale has the highest validity among the available scales (i.e. the Jackson/Cubbin, Norton, Waterlow and Choi/Song scales) (García-Fernández et al., 2013). By contrast, some other studies reported limitations of the Braden scale items

\section{What does this paper contribute to the wider global clinical community?}

- Age item for the Jackson/Cubbin scale and nutrition item for the Braden scale were poor predictors for ICU patients' PI risk assessment.

- Sedative and vasopressor medications, oedema, and CRF comorbidity as risk factors accounted for $58 \%$ of the change in the total score of the Braden scale.

in the assessment of ICU patient (Cox, 2012; Gül et al., 2016), and a low predictive validity for that scale in determining PI risk in the ICU population (Cho \& Noh, 2010; Hyun et al., 2013; LimaSerrano, González-Méndez, Martín-Castaño, Alonso-Araujo, \& Lima-Rodríguez, 2018). These discrepancies raise questions regarding the validity and reliability of the Braden scale as a risk assessment tool for ICU patients.

The recognition of these limitations led to the development of the Jackson/Cubbin scale specifically to assess PI risk in ICU patients. This scale consists of both general risk factors and ICU patient-specific risk factors and includes age, weight, past medical history, general skin condition, mobility, nutrition, incontinence, hygiene, mental condition, haemodynamics, respiration and oxygen requirement (Jackson, 1999). Nevertheless, the evidence supporting the use of the Jackson/Cubbin scale for assessing PI risk in ICU patients remains limited and contradictory. Some studies have reported that the Jackson/Cubbin scale is reliable and valid for PI risk assessment of ICU patients (Kim, Lee, Lee, \& Eom, 2009; Seongsook et al., 2004; Sousa, 2013). By contrast, Boyle and Green (2001) used an unrevised version of the scale and reported a low predictive validity of the scale to assess PI risk; therefore, they did not recommend use of this scale. These results indicate that further research is needed to determine the predictive validity (sensitivity, specificity, positive predictive value [PPV] and negative predictive value [NPV]) and reliability (Cronbach's alpha, which is a measure of internal consistency) of the two risk assessment scales, especially for use in ICU patients. In addition, the identification of risk factors that may have direct or indirect effects on the total score of the scale (at risk/not at risk) will improve the risk assessment quality and help nurses take preventive interventions according to patient-specific factors.

\section{\begin{tabular}{l|l}
1.2 & Aim
\end{tabular}}

The primary aim of this study was to compare the predictive validity and reliability of Braden and Jackson/Cubbin scales for assessing PI risk in ICU patients. The Braden scale is commonly used in all clinical areas, including ICUs (Balzer et al., 2007; Kılıç Fırat \& Sucudağ, 2017; Magnan \& Maklebust, 2009; Seongsook et al., 2004) but it has been criticised on the grounds of limited content, low validity and low interrater reliability (Cho \& Noh, 2010; Cox, 2012; Kottner \& Dassen, 2010). 
The Jackson/Cubbin scale was developed for use in ICU patients, but it has only been evaluated by a limited number of contradictory studies (Boyle \& Green, 2001; Kim et al., 2009; Seongsook et al., 2004; Sousa, 2013; Soyer, 2014). The effect of various risk factors on the total scores of both scales was also investigated in the present study.

\section{2 | METHODS}

\section{1 | Design}

This was a prospective design cross-sectional study (conducted over 6 months, from 1 November 2017-27 April 2018) adheres to the STARD guideline for diagnostic and accuracy studies (see Appendix S1).

\section{2 | Sample and setting}

The study was conducted in the 38-bed ICUs of a tertiary level, 730bed capacity university hospital (Ankara, Turkey). This hospital provides outpatient treatment for approximately 1,000,000 patients and inpatient treatment for 50,000 patients every year. The number of annual admissions to the ICUs is 2,160 patients. The study was conducted in the Internal Medicine, General Surgery, and Brain and Nerve Surgery ICUs of the hospital. There is no step down units (high dependency care units) apart from the ICUs in the hospital where the study was conducted. Step down unit patients also hospitalised in this ICUs. The mean length of patient stays in these ICUs is 7 days. The operational bed capacity is 18 beds for Internal Medicine, nine beds for General Surgery, and 11 beds for Brain and Nerve Surgery. In these ICUs, the Braden scale is used to assess the PI risk. The ICU nurses assess the patient's PI risk once a day or when a change occurs in the clinical situation of the patient. The ICU nurses implement the preventive interventions according to the hospital's "PI Prevention Protocol."

The inclusion criteria of the study were as follows: 18 years of age or older; no PIs evident at the time of admission to the ICU; and length of stay longer than $24 \mathrm{hr}$ in the ICU. The exclusion criterion of the study was the presence of a PI on admission. Overall, 483 ICU patients were contacted during the study period. Of the contacted patients, 307 were not included in the study as six of them were under 18 years of age, seven were hospitalised for $<24 \mathrm{hr}, 88$ were admitted with Pls and 206 did not agree to participate in the study. Thus, the final sample size consisted of 176 patients who met the inclusion criteria.

\section{3 | Data collection}

Data were collected with a case form and the Braden and Jackson/ Cubbin scales.

\subsection{1 | Case form}

The form was developed by the researchers based on literature concerning ICU patient characteristics and PI risk factors (Coleman et al., 2013; Keller, Wille, van Ramshorst, \& van der Werken, 2002; Manzano et al., 2010). The form consisted of the patients' sociodemographicclinical characteristics, such as gender, age, height, weight, body mass index (BMI), admission diagnosis, chronic diseases (comorbidity), level of consciousness according to the Glasgow Scale (GCS); levels of haemoglobin, leucocytes, albumin, total protein, and fasting blood glucose (FBG); and use of vasopressor, sedative, and steroid medication.

\subsubsection{Braden scale}

The scale was developed for the general patient population in 1987 and consists of six items: sensory perception, moisture, activity, mobility, friction and shear, and nutrition status. The "friction and shear" item is rated from 1-3, while the remaining items are rated from 1-4, so the lowest score is 6 and the highest score is 23; low scores on the Braden scale imply higher risk. Patients are classified at varying intervals from low risk to high risk according to the total score taken from the scale. The developers of the scale used a cut-off score of 16 (Bergstrom et al., 1987). In the present study, a validated Turkish version of the scale was used and the cut-off score was 16 (for patients considered at risk for PI) (Oğuz \& Olgun, 1998).

\subsection{3 | Jackson/Cubbin scale}

The scale was developed in 1991 for ICU patients and revised in 1999. The revised version of the scale consists of 12 items: age, weight, past medical history, general skin condition, mental condition, mobility, haemodynamics respiration, oxygen requirement, nutrition, incontinence and hygiene. Each item is rated from 1-4. If the patient has a body temperature below $36^{\circ} \mathrm{C}$ or has undergone transfusion of blood products in the last $24 \mathrm{hr}$ or radiological imaging (chest radiography, echocardiography, computed tomography or magnetic resonance imaging) in the last $48 \mathrm{hr}$, it is recommended 1-point deduction from the total score of the scale for each of these cases. In this study, the deduction points were handled according to the Turkish version of the scale. The Turkish version of the scale was reported one deduction for each case from the total score as the original scale recommendation. Accordingly, the lowest score of the scale is 9 and the highest score is 48 . Low scores on the Jackson/ Cubbin scale imply a higher risk. The cut-off score for the scale was 29 in the revised version (Jackson, 1999). In this study, the validated Turkish version was used and the cut-off score was 29 (Soyer, 2014).

During the study, the PI risk assessment was performed by one (the same) researcher. The researcher who conducted the PI risk assessment during the study worked as an ICU nurse in 2013-2015 and was trained in the use of the Braden Scale for assessing PI risk during Bachelor of Science in nursing education and in service education at the hospital. The researcher consulted with the author who had adapted the Jackson/Cubbin scale to Turkish to assess the PI risk with the Jackson/Cubbin Scale in ICU patients. In addition, before the start of the study, the researcher assessed patient risk with both the Braden and Jackson/Cubbin scales for a month in the study settings. 
The patients' sociodemographic and clinical information was collected with case forms. The patients' PI risk was assessed once a day (08.00-12.00 a.m.) with the Braden and Jackson/Cubbin scales. Each patient was assessed according to the items and sub-items of the scales. The risk assessments were conducted with both scales consecutively, and each assessment lasted about $15 \mathrm{~min}$. The order of the assessments was always the same (the Braden scale first, followed immediately by the Jackson/Cubbin scale). A patient's risk assessment was terminated on the day of PI development (Stage I) or when the patient was discharged from the ICU or died. The minimum risk assessment frequency was 3 and the maximum 86 (7, on average). The development of Pls was determined according to the 2016 National Pressure Ulcer Advisory Panel PI Staging System (National Pressure Ulcer Advisory Panel, 2016, 2016). The patient's skin condition according to the deterioration of skin integrity was evaluated as presence/absence. The patient's skin humidity according to dryness or excessive humidity was evaluated as presence/absence. The oedema status was evaluated as the presence/absence of pitting oedema ( $3 \mathrm{~s}$ of pressure was applied to the tibia to determine pitting oedema).

\section{4 | Ethical considerations}

The study was approved by the Non-Invasive Clinical Research Ethics Committee of a University (Decision No: GO 16969557-1082). The necessary permissions were also obtained from the ICUs (Internal Medicine, General Surgery, Brain and Nerve Surgery Departments). Permission was obtained for the use of the Jackson/Cubbin scale from the researcher who had adapted it to the Turkish language. Written informed consent was obtained from the patients or their legal guardians. All patients were volunteers.

\section{5 | Data analysis}

The patients' sociodemographic-clinical characteristics and incidence of $\mathrm{PI}$ were summarised using descriptive statistics. Frequencies (percentages) were used for categorical variables; the quantitative variables were not normally distributed, so the medians (interquartile range [IQR]) were used as descriptive statistics. According to the Youden Index, the predictive validity of the scales was calculated as sensitivity, specificity, positive predictive value (PPV) and negative predictive value (NPV). The receiver operating characteristic (ROC) curve was generated, and the area under the curve (AUC) was reported. As a reliability measure, the internal consistency of the scales was calculated. For the internal consistency, the Spearman correlation coefficient between the items of the scale and total scores, as well as the Cronbach's alpha coefficient, was calculated. To assess the risk factors affecting the Braden scale, the total scores were evaluated with multiple linear regression analysis and a stepwise model. Since the risk factors included in the regression analysis were also items or sub-items of the Jackson/Cubbin scale, the scale was excluded from the regression analysis. A value of $p<.05$ was considered statistically significant. Data were analysed using IBM SPSS Statistics for Windows version 23.0 (IBM Corp.).
Sensitivity is defined as the probability that the risk assessment scale result is positive (at risk) when given to a group of patients who have PIs. Specificity is defined as the probability that the risk assessment scale result will be negative (not at risk) among patients who do not have PIs. The PPV is the probability that a patient who had a positive risk assessment scale result for a PI actually has a PI. The NPV is the probability that a patient who had a negative risk assessment scale result for the PI will not have a PI (Munro, 2005). The ROC curve analysis graphically portrays a series of sensitivities and specificities for the risk assessment scales. The sensitivity is plotted on the vertical axis against the specificity on the horizontal axis over a range of potential cut-off scores. The score where mean sensitivity and specificity values are highest is the optimal cut-off score. The cut-off score plays a role in discriminating the patient's PI risk assessment total score by determining the patient as being "at risk" or "not at risk." Therefore, the cut-off score is important for identifying the patient's risk assessment outcome. The AUC is a commonly used summary measure for ROC curves. Higher AUC values indicate more accurate assessment results. When the risk assessment scale has no discriminatory ability to determine PI risk, the AUC would equal .5. Cronbach's alpha is an indicator of the internal consistency of the scale. If the Cronbach's alpha value is . 70 and above, the scale items deemed to be consistent within themselves. The consistency in measuring the outcome variable infers the reliability of the scale (Alpar, 2016).

\subsection{1 | Sample size}

The adequacy of the sample size was evaluated by poststudy power analysis performed separately for both scales (Li \& Fine, 2004; Obuchowski \& Zhou, 2002). For the Braden scale, a total sample size of 176 patients (which includes 24 patients with the PIs) achieves $100 \%$ power to detect a change in sensitivity from .5-.958 using a two-sided binomial test and $100 \%$ power to detect a change in specificity from .5-.631 using a two-sided binomial test. The actual significance level achieved by the sensitivity test was .0227 and achieved by the specificity test was .0422 . The incidence of PI was .1363. The target significance level was .05 .

For the Jackson/Cubbin scale, a total sample size of 176 patients (which includes 24 patients with the PIs) achieves 91\% power to detect a change in sensitivity from .5-.833 using a two-sided binomial test and $100 \%$ power to detect a change in specificity from .5-.862 using a two-sided binomial test. The actual significance level achieved by the sensitivity test was .0227 and achieved by the specificity test was .0422 . The incidence of the PI was .1363. The target significance level was .05 .

\section{3 | RESULTS}

\section{1 | Demographic and clinical characteristics of the ICU patients}

The study sample consisted of 176 patients from 3 ICUs; the PI incidence was $13.6 \%$. The sacrococcygeal area was the most frequent 
TABLE 1 Sociodemographic and clinical characteristics of the patients $(n=176)$

\begin{tabular}{|c|c|c|}
\hline $\begin{array}{l}\text { Sociodemographic } \\
\text { characteristics }\end{array}$ & $n(\%)$ & $\begin{array}{l}\text { Median (interquartile } \\
\text { range [IQR]) }\end{array}$ \\
\hline Age (year) & & $61(49.25-71.0)$ \\
\hline \multicolumn{3}{|l|}{ Sex } \\
\hline Female & $80(45.5)$ & \\
\hline Male & $96(54.5)$ & \\
\hline Body mass index & & $25.57(22.79-29.46)$ \\
\hline \multicolumn{3}{|l|}{ Habits } \\
\hline $\begin{array}{l}\text { Tobacco use and alcohol } \\
\text { consumption }\end{array}$ & $5(2.8)$ & \\
\hline Tobacco use & $33(18.8)$ & \\
\hline No & $138(78.4)$ & \\
\hline \multicolumn{3}{|l|}{ Clinical characteristics } \\
\hline APACHE-II scores & & $14(11-21)$ \\
\hline \multicolumn{3}{|c|}{ Distribution of the patients according to ICUs } \\
\hline Brain and nerve surgery & $26(14.8)$ & \\
\hline General surgery & $74(42.0)$ & \\
\hline Internal medicine & $76(43.2)$ & \\
\hline Length of ICU stay (day) & & $7(5-12)$ \\
\hline \multicolumn{3}{|l|}{ Admitting diagnosis $^{a}$} \\
\hline Cerebrovascular diseases & $28(15.9)$ & \\
\hline $\begin{array}{l}\text { Respiratory system } \\
\text { diseases }\end{array}$ & $47(26.7)$ & \\
\hline Other problems ${ }^{b}$ & $49(27.9)$ & \\
\hline Major surgery/trauma & $59(33.5)$ & \\
\hline $\begin{array}{l}\text { Gastrointestinal system } \\
\text { diseases }\end{array}$ & $62(35.2)$ & \\
\hline \multicolumn{3}{|l|}{ Comorbid conditions $^{a}$} \\
\hline Chronic renal failure & $15(8.5)$ & \\
\hline Chronic cardiac failure & $21(11.9)$ & \\
\hline $\begin{array}{l}\text { Chronic obstructive } \\
\text { pulmonary disease }\end{array}$ & $25(14.2)$ & \\
\hline Obesity & $41(23.3)$ & \\
\hline Diabetes mellitus & $55(31.3)$ & \\
\hline Cancer & $71(40.3)$ & \\
\hline \multicolumn{3}{|l|}{ Glasgow scale score } \\
\hline Score 3 (coma) & $31(17.6)$ & \\
\hline $\begin{array}{l}\text { Score 4-14 (disoriented, } \\
\text { stupor, precoma) }\end{array}$ & $29(16.5)$ & \\
\hline Score 15 (oriented) & $116(65.9)$ & \\
\hline \multicolumn{3}{|l|}{ Medications $(n=86)$} \\
\hline Sedatives $^{c}$ & $25(14.2)$ & \\
\hline Vasopressors $^{d}$ & $27(15.3)$ & \\
\hline Steroids ${ }^{\mathrm{e}}$ & $34(19.3)$ & \\
\hline \multicolumn{3}{|l|}{ Laboratory values } \\
\hline $\begin{array}{l}\text { Haemoglobin }(\mathrm{g} / \mathrm{dl}) \\
(n=176)\end{array}$ & & $10.60(9.22-11.77)$ \\
\hline
\end{tabular}

(Continues)
TABLE 1 (Continued)

\begin{tabular}{|c|c|c|}
\hline $\begin{array}{l}\text { Sociodemographic } \\
\text { characteristics }\end{array}$ & $n(\%)$ & $\begin{array}{l}\text { Median (interquartile } \\
\text { range [IQR]) }\end{array}$ \\
\hline $\begin{array}{l}\text { Leucocyte }\left(\times 10^{3} / \mu \mathrm{l}\right) \\
\quad(n=175)\end{array}$ & & $9.0(6.2-13.0)$ \\
\hline $\begin{array}{l}\text { Total protein }(\mathrm{g} / \mathrm{dl}) \\
(n=175)\end{array}$ & & $5.65(5.19-6.24)$ \\
\hline Albumin (g/dl) $(n=174)$ & & $2.73(2.39-3.07)$ \\
\hline $\begin{array}{l}\text { Fasting blood sugar (mg/ } \\
\text { dl) }(n=151)\end{array}$ & & $13(108.0-161.0)$ \\
\hline \multicolumn{3}{|l|}{ Oedema } \\
\hline Yes & $36(20.5)$ & \\
\hline No & $140(79.5)$ & \\
\hline \multicolumn{3}{|l|}{ PI incidence among to ICUs } \\
\hline General surgery & $4(2.3)$ & \\
\hline Brain and nerve surgery & $8(4.5)$ & \\
\hline Internal medicine & $12(6.8)$ & \\
\hline Total & $24(13.6)$ & \\
\hline \multicolumn{3}{|l|}{ Location of Pls } \\
\hline Scapula & $1(4.2)$ & \\
\hline Trochanter & $3(12.5)$ & \\
\hline Buttocks & $3(12.5)$ & \\
\hline Sacrum and coccyx & $17(70.8)$ & \\
\hline
\end{tabular}

a"One patient had more than one admitting diagnosis" and "One patient had more than one comorbid condition."

${ }^{b}$ Crohn's disease, general condition disorder, Hashimoto's thyroiditis, sepsis.

${ }^{\mathrm{c}}$ Fentanyl, midazolam, propofol, remifentanil.

${ }^{\mathrm{d}}$ Epinephrine, dobutamine, dopamine, norepinephrine.

${ }^{\mathrm{e}}$ Dexamethasone, methylprednisolone.

location (70.8\%). The median age of patients was 61 years (IQR, 49.25$71.0) ; 54.5 \%$ of patients were male, and $43.2 \%$ were hospitalised in the internal medicine ICU and $42.0 \%$ in the general surgery ICU. Of the patients, $33.5 \%$ were hospitalised for major surgical interventions, $35.2 \%$ for gastrointestinal complications and $26.7 \%$ for respiratory system diseases. The median length of ICU stay was 7 days (IQR, 5-12). Overall, $65.9 \%$ of patients were conscious, $15.3 \%$ received vasopressor medications, and $14.2 \%$ received sedative medications. The median haemoglobin concentration was 10.60 (IQR, 9.22-11.77); $20.5 \%$ of patients had grade $1+$ and above pitting oedema on the tibia (Table 1).

\subsection{Reliability of the scales}

The Cronbach's alpha coefficient was .78 for the Jackson/Cubbin scale and .85 for the Braden scale. A weak, positive and statistically significant correlation was found between the Jackson/Cubbin scale item "Age" and the total score of the scale ( $r=.27)$. A strong, positive and statistically significant correlation was found between the Jackson/Cubbin scale items "Mobility" ( $r=.81)$ and "Hygiene" $(r=.83)$ and the total score of the scale. The Braden scale item "Nutrition" had a weak, positive and statistically significant correlation with the total score of the scale $(r=.29)$. The Braden scale items "Activity" 
TAB LE 2 Scale items and total score correlations

\begin{tabular}{|c|c|c|}
\hline Scale & Items & $r$ \\
\hline \multirow{12}{*}{$\begin{array}{l}\text { Jackson/ } \\
\text { Cubbin } \\
\text { scale }\end{array}$} & 1. Age & $.27^{*}$ \\
\hline & 2. Weight, tissue viability & $.46^{*}$ \\
\hline & 3. Past medical history-affecting condition & $.56^{*}$ \\
\hline & 4. General skin condition & $.53^{*}$ \\
\hline & 5. Mental condition & $.73^{*}$ \\
\hline & 6. Mobility & $.81^{*}$ \\
\hline & 7. Haemodynamics & $.52^{*}$ \\
\hline & 8. Respiration & $.71^{*}$ \\
\hline & 9. Oxygen requirements & $.48^{*}$ \\
\hline & 10. Nutrition & $.44^{*}$ \\
\hline & 11. Incontinence & $.72^{*}$ \\
\hline & 12. Hygiene & $.83^{*}$ \\
\hline \multirow{6}{*}{$\begin{array}{l}\text { Braden } \\
\text { scale }\end{array}$} & 1. Sensory perception & $.83^{*}$ \\
\hline & 2. Moisture & $.39^{*}$ \\
\hline & 3. Activity & $.93^{*}$ \\
\hline & 4. Mobility & $.95^{*}$ \\
\hline & 5. Nutrition & $.29^{*}$ \\
\hline & 6. Friction and shear & $.88^{*}$ \\
\hline
\end{tabular}

${ }^{*} p<.001$.

$(r=.93)$ and "Mobility" ( $r=.95)$ had positive, strong and statistically significant correlations with the total score of the scale (Table 2).

\section{3 | Predictive validities and ROC analyses of the scales}

The sensitivity and specificity of the Jackson/Cubbin scale were 83.3 and 86.1, respectively, while those of the Braden scale were 95.8 and
63.1, respectively (Table 3 ). The area under the ROC curves of the Jackson/Cubbin scale was .86 (95\% confidence interval .810-.910), and the Braden scale was .86 (95\% confidence interval .800-.908) (Figure 1).

\section{4 | Risk factors affecting the total score of the Braden scale}

The multiple linear regression analysis between the Braden scale total score and PI risk factors (age, gender, length of ICU stay, comorbidity [obesity, DM, COPD, CHF, CRF and Ca], oedema, vasopressor, sedative, steroid medications, haemoglobin, leucocyte, total protein, albumin and fasting blood glucose values) resulted in five steps. In the final model (model 5), sedative and vasopressor medications, oedema, and the presence of CRF comorbidity led to a statistically significant decrease of $.35, .30, .19$ and .11 units, respectively, in the total score of the Braden scale. These risk factors also accounted for $58 \%$ of the change in the total score of the Braden scale $\left(R^{2} a=.58\right)$ (Table 4$)$.

\section{DISCUSSION}

The use of a valid and reliable risk assessment tool is reported to increase the frequency and effectiveness of PI preventive interventions, based on the risk assessment factors (Pancorbo-Hidalgo, Garcia-Fernandez, Lopez-Medina, \& Alvarez-Nieto, 2006). This improvement in interventions will also increase the quality of nursing care and protect the patients from unnecessary procedures. Therefore, determining a valid and reliable risk assessment tool is important for ICU patients, as these patients have many PI risk factors and are prone to PI development.

TABLE 3 Predictive validity of the Jackson/Cubbin and Braden scales

\begin{tabular}{|llllll} 
& Cut-off point & Sensitivity $\left(95 \% \mathrm{Cl}^{\mathrm{a}}\right)$ & Specificity (95\% Cl) & PPV (95\% Cl) & NPV (95\% Cl) \\
\hline Jackson/Cubbin & $\leq 28$ & $83.3(62.6-95.3)$ & $86.8(80.4-91.8)$ & $50.0(33.8-66.2)$ & $97.1(92.6-99.2)$ \\
scale & $\leq 29$ & $83.3(62.6-95.3)$ & $86.1(79.7-91.2)$ & $48.8(32.9-64.9)$ & $97.0(92.6-99.2)$ \\
& $\leq 30$ & $87.5(67.6-97.3)$ & $84.8(78.2-90.2)$ & $47.7(32.5-63.3)$ & $97.7(93.5-99.5)$ \\
& $\leq 31$ & $91.6(73.0-99.0)$ & $80.2(73.0-86.3)$ & $42.3(28.7-56.8)$ & $98.4(94.3-99.8)$ \\
& $\leq 32$ & $95.8(78.9-99.9)$ & $76.3(68.7-82.8)$ & $39.0(26.5-52.6)$ & $99.1(95.3-100.0)$ \\
& $\leq 33$ & $95.8(78.9-99.9)$ & $67.7(59.7-75.1)$ & $31.9(21.4-44.0)$ & $99.0(94.8-100.0)$ \\
Braden scale & $\leq 34$ & $95.8(78.9-99.9)$ & $61.1(53.0-69.0)$ & $28(18.7-39.1)$ & $98.9(94.2-100.0)$ \\
& $\leq 12$ & $75(53.3-90.2)$ & $83.5(76.7-89.1)$ & $41.9(27.0-57.9)$ & $95.5(90.4-98.3)$ \\
& $\leq 13$ & $79.1(57.8-92.9)$ & $82.2(75.2-88.0)$ & $41.3(27.0-56.8)$ & $96.2(91.3-98.7)$ \\
& $\leq 14$ & $87.5(67.6-97.3)$ & $81.5(74.5-87.4)$ & $42.9(28.8-57.8)$ & $97.6(93.3-99.5)$ \\
& $\leq 15$ & $95.8(78.9-99.9)$ & $75.6(68.0-82.2)$ & $38.3(26.1-51.8)$ & $99.1(95.3-100.0)$ \\
& $\leq 16$ & $95.8(78.9-99.9)$ & $63.1(55.0-70.8)$ & $29.1(19.4-40.4)$ & $99.0(94.4-100.0)$ \\
& $\leq 17$ & $95.8(78.9-99.9)$ & $52.6(44.4-60.8)$ & $24.2(16.0-34.1)$ & $98.8(93.3-100.0)$ \\
& $\leq 18$ & $95.8(78.9-99.9)$ & $44.1(36.0-52.4)$ & $21.3(14.0-30.2)$ & $98.5(92.1-100.0)$
\end{tabular}

${ }^{\mathrm{a}}$ Confidence interval. 


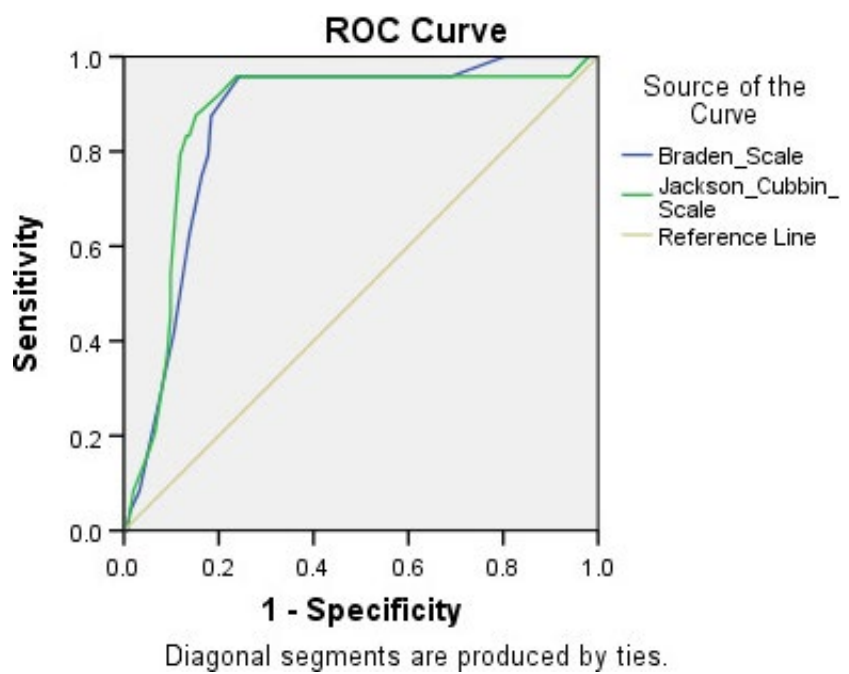

FIG URE 1 ROC curve of the Jackson/Cubbin and Braden scales

\section{1 | Study sample}

In this study, the patients (65.9\%) who were oriented and (34.1\%) who had a change in the level of consciousness (disoriented, stupor, precoma and coma) were required close medical follow-up or needed advanced life support because of their clinical manifestations. At the same time, all patients were dependent on meeting their basic needs (nutrition, urinary and intestinal elimination, mobilisation, etc.). Therefore, patients were considered at risk regardless of the risk assessment result and standard PI preventive interventions were implemented for all patients. As a result of these preventive interventions, the number of patients who develop PIs was small.

\section{2 | Reliability of the scales}

In this study, the reliability of the Jackson/Cubbin and Braden scales was evaluated by internal consistency (scale item-total score correlations, Cronbach's alpha coefficient).The correlation coefficient indicates that each item of the scale should be correlated with the total score of the scale with a value of .30 or above for internal consistency (Munro, 2005). In this respect, a higher correlation coefficient between the item and the total score gives a better correlation between the item and the outcome measure. In this study, the correlation coefficients between the items and the total score of both scales were above .30, except for "age" as an item for the Jackson/ Cubbin scale and "nutrition" as an item for the Braden scale. In a comprehensive review in which the predictive power of the PI risk of the Braden scale was analysed, it was reported that "nutrition" item was not predictive PI development in ICU patients (Cox, 2012). This finding of the Cox's (2012) study is consistent with our results. In general, both statistically and clinically, the age and nutrition items would be expected to have strong correlations with the total score of the scales. This is because ageing decreases the subcutaneous collagen tissue, skin elasticity and skin turgor, thereby increasing the risk of PI. Changes in nutritional status (such as lack of oral intake and malnutrition) also increase skin susceptibility to PI development. In the present study, the patient age had a heterogeneous distribution from young to old. In addition, independently from their ages, the patients had complex clinical manifestations. These factors may have affected the correlation coefficient outcomes of the age item. In addition, the nutritional status assessment of the ICU patients is not limited only to food intake, as it also contains objective parameters, such as serum albumin, total protein, mineral and vitamin levels (Diker, Öntürk, Badır, \& Aslan, 2009). However, in the Braden scale,

TA B LE 4 The effect of pressure injury risk factors on Braden scale's total score (multiple linear regression analysis, stepwise method) ${ }^{a}$

\begin{tabular}{|c|c|c|c|c|c|c|c|c|c|}
\hline \multirow[b]{2}{*}{ Model } & \multirow[b]{2}{*}{ Variables } & \multicolumn{2}{|c|}{$\begin{array}{l}\text { Unstandardised } \\
\text { coefficients }\end{array}$} & \multirow[b]{2}{*}{$p$} & \multirow[b]{2}{*}{$95 \% \mathrm{Cl}^{\mathrm{b}}$} & & \multirow[b]{2}{*}{$R$} & \multirow[b]{2}{*}{$R^{2} a$} & \multirow[b]{2}{*}{$p$} \\
\hline & & B & SE & & & & & & \\
\hline \multirow[t]{2}{*}{1} & Constant & 17.152 & 0.271 & $<.001$ & 16.617 & 17.687 & \multirow[t]{2}{*}{.661} & \multirow[t]{2}{*}{.433} & \multirow[t]{2}{*}{$<.001$} \\
\hline & Sedatives & -7.194 & 0.674 & $<.001$ & -8.526 & -5.861 & & & \\
\hline \multirow[t]{2}{*}{2} & Constant & 17.448 & 0.257 & $<.001$ & 16.94 & 17.957 & \multirow[t]{2}{*}{.721} & \multirow[t]{2}{*}{.514} & \multirow[t]{2}{*}{$<.001$} \\
\hline & Vasopressors & -3.706 & 0.735 & $<.001$ & -5.158 & -2.253 & & & \\
\hline \multicolumn{10}{|l|}{$\ldots$} \\
\hline \multirow[t]{3}{*}{5} & Constant & 14.391 & 1.155 & $<.001$ & 12.108 & 16.675 & \multirow[t]{3}{*}{.776} & \multirow[t]{3}{*}{.588} & \multirow[t]{3}{*}{$<.001$} \\
\hline & Sedatives & -3.855 & 0.779 & $<.001$ & -5.394 & -2.315 & & & \\
\hline & CRF & -1.474 & 0.722 & .043 & -2.902 & -0.046 & & & \\
\hline
\end{tabular}

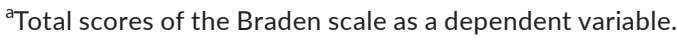

${ }^{\mathrm{b}}$ Confidence interval.

${ }^{\mathrm{C}}$ Constant refers to the constant value in the multiple linear regression analysis. 
the nutritional status assessment is limited only to food intake, so this may affect the correlation coefficient outcome of the nutrition item.

A Cronbach's alpha coefficient of .70 and above indicates that the scale items are consistent within themselves and measure the same outcome variable; that is, the scale is reliable. In this study, the Cronbach's alpha coefficients were above .70 for both Jackson/ Cubbin and Braden scales. In other words, both scales were found reliable. In a previous study (Sousa, 2013), Cronbach's alpha coefficient of Jackson/Cubbin scale was reported similar to our study. On the other hand, the Cronbach's alpha coefficient of the Braden scale was higher than the value obtained in a study conducted by different raters (Lima-Serrano et al., 2018); indeed, the reliability of the Braden scale is reportedly affected by inter-rater differences (Kottner \& Dassen, 2010). In this study, the patient PI risk was assessed by the same researcher throughout the study; therefore, the calculated Cronbach's alpha coefficient of the Braden Scale was thought to be high.

\subsection{Predictive validity of the scales}

The sensitivity, specificity, PPV and NPV of the Jackson/Cubbin scale were 83.3, 86.1, 48.8 and 97.0, respectively, while those of the Braden scale were 95.8, 63.1, 29.1 and 99.0, respectively. Other studies conducted with ICU patients have reported Jackson/Cubbin scale sensitivity values ranging from 55.8-93.3, specificity values ranging from 41.3-81.3, PPV ranging from 13.3-50.0 and NPV ranging from 87.5-98.3 (Ahtiala, Soppi, \& Kivimäki, 2016; Ahtiala, Soppi, Wiksten, Koskela, \& Grönlund, 2014; García-Fernández et al., 2013; Sousa, 2013). Previous studies on ICU patients have reported Braden scale sensitivity values ranging from $71.4-100$, specificity values ranging from 7.0-83.1, PPV ranging from 13.6-73.5 and NPV ranging from 66.7-100 (Cox, 2012; Hyun et al., 2013; Kim et al., 2009; Lima-Serrano et al., 2018; Serpa, Santos, Campanili, \& Queiroz, 2011; Sousa, 2013). The results of these other studies, as well as the present study, indicate that the sensitivity, specificity and PPV of the Jackson/ Cubbin scale vary from low to high values, but the NPVs are consistently high. By contrast, the sensitivity and NPV of the Braden scale were consistently high in different studies, while the specificity and PPV varied from low to high values.

A high NPV is an advantage for discriminating those patients who are truly not at risk, but the PI risk assessment's primary objective is to determine the patients at risk. For this reason, if both the sensitivity and specificity values are high for a scale, the discriminative ability between the patients at risk and not at risk will be high. In this context, risk assessment tools should have high sensitivity and specificity values. However, a scale with high sensitivity and low specificity will identify most of the patients at risk for PI, but the scale's predictive ability might be misleading for the patients not at risk. Therefore, both the sensitivity and specificity of a scale should be consistently high. In the present study, the Jackson/Cubbin scale had high values for both sensitivity and specificity, whereas the Braden scale sensitivity value was higher than the specificity value. These findings indicate that the predictive ability to determine the patients at risk and not at risk for PI was better for the Jackson/Cubbin scale than for the Braden scale.

A high PPV is an advantage for discriminating those patients who are truly at risk, but the PI rates, inter-rater differences and patient characteristics affect the same scale's PPV and optimal cutoff points. Among the studies if the patients' PI risk is assessed in an ICU which has high prevalence or incidence rates, patients who are at PI risk are more likely to develop the PIs, considering in a low prevalence population. This leads to high PPV of the studies conducted with the same scale (Braden scale) and the similar population (ICU patients). If a scale has items that may cause inter-rater differences, this also affects the overall risk score and cut-off point of the scale. The differences of the patients' clinical manifestations among the studies similarly affect the predictive validity results. Therefore, the sensitivity, specificity and also cut-off points are affected by the patients' clinical manifestations and inter-rater differences among the studies. In the present study, sensitivity, specificity, PPV, NPV and cut-off score were 95.8, 63.1, 29.1, 99.0 and 16, respectively; Hyun et al. (2013) were reported these values as 95.4, 20.7, 11.4, 97.7 and 13, respectively (Hyun et al., 2013). Because of differences in PI rates, inter-raters and patient characteristics between the two studies; the Braden scale's predictive validity values and optimal cut-off points were found to be different. In other words, PI incidence was found to be $13.6 \%$ in our study and the PI risk assessment was conducted by one researcher during the study. Hyun et al. (2013) had reported the prevalence of Pls $9.7 \%$, and they collected their data from electronic health records (Hyun et al., 2013).

\subsection{Risk factors affecting total score of the scales}

As stated previously, ICU patients have many risk factors that may increase the risk of PI development, both in general and individually. Therefore, the risk assessment in ICU patients should not be limited only to the parameters of the risk assessment tool. In the present study, all available patient-related factors were analysed according to their effects on the total score of the Braden scale. Of these factors, oedema, CRF, and sedative and vasopressor medication treatment affected the total score of the scale by .58. Another study conducted with ICU patients reported that age, acute physiological status and nursing activities (patient care, treatment, and follow-up; administrative tasks; and support and care provided to patient's family members) affected the total score of the Braden scale by .45 (Cremasco, Wenzel, Zanei, \& Whitaker, 2013). The present analysis showed that, in addition to the risk parameters evaluated by the scale, other patient factors could also increase the risk of PI. Therefore, the ICU nurses should take these other risk factors (oedema, CRF, and sedative and vasopressor medications) into consideration when assessing their patients' PI risk according to Braden scale. They should also take appropriate measures to address these risk factors. 


\section{5 | STUDY LIMITATIONS}

In the study settings, the patients' risk was assessed with the Braden scale by the nurses as well and preventive interventions were implemented accordingly. These preventive nursing interventions were probably based on the Braden scale and might have influenced the description of the incidence of PI.

\section{6 | CONCLUSION}

The results of this study indicate that both the Braden and the Jackson/Cubbin scales are valid and reliable for identifying the PI risk in ICU patients. However, the Jackson/Cubbin scale has better predictive validity than the Braden scale, according to its overall sensitivity and specificity values. Oedema, CRF, and sedative and vasopressor medication treatments were factors affecting the Braden scale's total score by $1 / 2$. Therefore, ICU nurses should take these factors into consideration when assessing their patients with the Braden scale.

\section{7 | RELEVANCE TO CLINICAL PRACTICE}

In the ICU, the most commonly used PI risk assessment tool is the Braden scale. Braden scale assesses the main risk factors, but not all risk factors, that may cause PIs in ICU patients. Jackson/Cubbin scale specifically developed to assess PI risk in ICU patients. This scale consists of both general risk factors and ICU patient-specific risk factors. Both scales are reliable and valid scales for PI risk assessment. Jackson/Cubbin scale's discriminative ability (between the patients at PI risk and not at PI risk) was better.

\section{ACKNOWLEDGMENTS}

The authors thank the patients and their legal guardians who agreed to participate in this study and the health professionals of the participating ICUs.

\section{CONFLICT OF INTEREST}

The authors declared that they have no conflict of interest or relationship, financial or otherwise, or personal, religious or political beliefs.

\section{AUTHOR CONTRIBUTIONS}

Data acquisition, analysis, results and interpretation: Seyma ADIBELLI; conception and design of this study, interpretation and discussion of the results, and revising the manuscript critically: Fatos KORKMAZ; and final version of this manuscript is approved by all of the authors.
ORCID

Seyma Adibelli (iD https://orcid.org/0000-0001-6131-4634

\section{REFERENCES}

Ahtiala, M. H., Soppi, E., \& Kivimäki, R. (2016). Critical evaluation of the Jackson/Cubbin Pressure Ulcer Risk Scale-A secondary analysis of a retrospective cohort study population of intensive care patients. Ostomy/wound Management, 62(2), 24.

Ahtiala, M. H., Soppi, E. T., Wiksten, A., Koskela, H., \& Grönlund, J. A. (2014). Occurrence of pressure ulcers and risk factors in a mixed medical-surgical ICU-A cohort study. Journal of the Intensive Care Society, 15(4), 340-343. https://doi.org/10.1177/175114371401500415

Alderden, J., Rondinelli, J., Pepper, G., Cummins, M., \& Whitney, J. (2017). Risk factors for pressure injuries among critical care patients: A systematic review. International Journal of Nursing Studies, 71, 97-114. https://doi.org/10.1016/j.ijnurstu.2017.03.012

Alpar, R. (2016). Applied statistics and validity-reliability. Ankara, Turkey: Detay Publishing.

Australian Wound Management Association (2012). Pan Pacific Clinical Practice Guideline for the Prevention and Management of Pressure Injury. Retrieved from http://www.woundsaustralia.com.au/publi cations/2012_AWMA_Pan_Pacific_Guidelines.pdf

Balzer, K., Pohl, C., Dassen, T., \& Halfens, R. (2007). The Norton, Waterlow, Braden, and Care Dependency Scales comparing their validity when identifying patients' pressure sore risk. Journal of Wound Ostomy \& Continence Nursing, 34(4), 389-398. https://doi. org/10.1097/01.WON.0000281655.78696.00

Becker, D., Tozo, T. C., Batista, S. S., Mattos, A. L., Silva, M. C. B., Rigon, S., ... Duarte, P. A. D. (2017). Pressure ulcers in ICU patients: Incidence and clinical and epidemiological features: A multicenter study in southern Brazil. Intensive and Critical Care Nursing, 42, 55-61. https:// doi.org/10.1016/j.iccn.2017.03.009

Bergstrom, N., Braden, B. J., Laguzza, A., \& Holman, V. (1987). The Braden scale for predicting pressure sore risk. Nursing Research, 36(4), 205210. https://doi.org/10.1097/00006199-198707000-00002

Bly, D., Schallom, M., Sona, C., \& Klinkenberg, D. (2016). A model of pressure, oxygenation, and perfusion risk factors for pressure ulcers in the intensive care unit. American Journal of Critical Care, 25(2), 156164. https://doi.org/10.4037/ajcc2016840

Boyle, M., \& Green, M. (2001). Pressure sores in intensive care: Defining their incidence and associated factors and assessing the utility of two pressure sore risk assessment tools. Australian Critical Care, 14(1), 24-30. https://doi.org/10.1016/S1036-7314(01)80019-9

Cho, I., \& Noh, M. (2010). Braden Scale: Evaluation of clinical usefulness in an intensive care unit. Journal of Advanced Nursing, 2(66), 293-302. https://doi.org/10.1111/j.1365-2648.2009.05153.x

Coleman, S., Gorecki, C., Nelson, E. A., Closs, S. J., Defloor, T., Halfens, R., ... Nixon, J. (2013). Patient risk factors for pressure ulcer development: Systematic review. International Journal of Nursing Studies, 50(7), 974-1003. https://doi.org/10.1016/j.ijnurstu.2012.11.019

Cox, J. (2012). Predictive power of the Braden Scale for pressure sore risk in adult critical care patients: A comprehensive review. Journal of Wound Ostomy \& Continence Nursing, 39(6), 613-621. https://doi. org/10.1097/WON.0b013e31826a4d83

Cox, J. (2017). Pressure injury risk factors in adult critical care patients: A review of the literature. Ostomy Wound Management, 63(11), 30-43.

Coyer, F., Miles, S., Gosley, S., Fulbrook, P., Sketcher-Baker, K., Cook, J.-L., \& Whitmore, J. (2017). Pressure injury prevalence in intensive care versus non-intensive care patients: A state-wide comparison. Australian Critical Care, https://doi.org/10.1016/j. aucc.2016.12.003 
Cremasco, M. F., Wenzel, F., Zanei, S. S., \& Whitaker, I. Y. (2013). Pressure ulcers in the intensive care unit: The relationship between nursing workload, illness severity and pressure ulcer risk. Journal of Clinical Nursing, 22(15-16), 2183-2191. https://doi. org/10.1111/j.1365-2702.2012.04216.x

de Almeida Medeiros, A. B., da Conceição Dias Fernandes, M. I., de Sá Tinôco, J. D., Cossi, M. S., de Oliveira Lopes, M. V., \& de Carvalho Lira, A. L. B. (2018). Predictors of pressure ulcer risk in adult intensive care patients: A retrospective case-control study. Intensive and Critical Care Nursing, 45, 6-10. https://doi.org/10.1016/j. iccn.2017.09.007

Diker, T., Öntürk, Z. K., Badır, A., \& Aslan, F. E. (2009). Nutritional requirement in intensive care patients. Journal of Intensive Care Nursing, 13(2), 90-93.

El-Marsi, J., Zein-El-Dine, S., Zein, B., Doumit, R., \& Badr, L. K. (2018). Predictors of pressure injuries in a critical care unit in Lebanon: Prevalence, characteristics, and associated factors. Journal of Wound Ostomy \& Continence Nursing, 45(2), 131-136. https://doi. org/10.1097/WON.0000000000000415

García-Fernández, F. P., Pancorbo-Hidalgo, P. L., \& Agreda, J. J. S. (2013). Risk assessment scales for pressure ulcer in intensive care units: $A$ systematic review with metaanalysis. European Wound Management Association Journal, 13(2), 7-13.

González-Méndez, M. I., Lima-Serrano, M., Martín-Castaño, C., AlonsoAraujo, I., \& Lima-Rodríguez, J. S. (2018). Incidence and risk factors associated with the development of pressure ulcers in an intensive care unit. Journal of Clinical Nursing, 27(5-6), 1028-1037. https://doi. org/10.1111/jocn.14091

Gül, Y. G., Köprülü, A. Ş., Haspolat, A., Uzman, S., Toptaş, M., \& Kurtuluş, i. (2016). Is Braden Scale reliable and sufficient to evaluate the risk of pressure ulcer occurrence in level 3 intensive care unit patients? Journal of Academic Research in Medicine, 6(2), 98-104. https://doi. org/10.5152/jarem.2016.969

Haesler, E., National Pressure Ulcer Advisory Panel, European Pressure Ulcer Advisory Panel, \& Pan Pacific Pressure Injury Alliance (2014). Prevention and treatment of pressure ulcers: Clinical practice guideline. Osborne Park, Australia: Cambridge Media.

Hyun, S., Vermillion, B., Newton, C., Fall, M., Li, X., Kaewprag, P., ... Lenz, E. R. (2013). Predictive validity of the Braden Scale for patients in intensive care units. American Journal of Critical Care, 22(6), 514-520. https://doi.org/10.4037/ajcc2013991

Jackson, C. (1999). The revised Jackson/Cubbin pressure area risk calculator. Intensive and Critical Care Nursing, 15(3), 169-175. https://doi. org/10.1016/S0964-3397(99)80048-2

Jenkins, M. L., \& O'Neal, E. (2010). Pressure ulcer prevalence and incidence in acute care. Advances in Skin \& Wound Care, 23(12), 556-559. https://doi.org/10.1097/01.ASW.0000391184.43845.c1

Keller, P. B., Wille, J., van Ramshorst, B., \& van der Werken, C. (2002). Pressure ulcers in intensive care patients: A review of risks and prevention. Intensive Care Medicine, 28(10), 1379-1388. https://doi. org/10.1007/s00134-002-1487-z

Kılıç Fırat, H., \& Sucudağ, G. (2017). The scales frequently used in the assessment of pressure sores. JAREN, 3(1), 49-54.

Kim, E.-K., Lee, S.-M., Lee, E., \& Eom, M.-R. (2009). Comparison of the predictive validity among pressure ulcer risk assessment scales for surgical ICU patients. Australian Journal of Advanced Nursing, 26(4), 87-94.

Kottner, J., \& Dassen, T. (2010). Pressure ulcer risk assessment in critical care: Interrater reliability and validity studies of the Braden and Waterlow scales and subjective ratings in two intensive care units. International Journal of Nursing Studies, 47(6), 671-677. https://doi. org/10.1016/j.ijnurstu.2009.11.005

Li, J., \& Fine, J. (2004). On sample size for sensitivity and specificity in prospective diagnostic accuracy studies. Statistics in Medicine, 23, 2537-2550. https://doi.org/10.1002/sim.1836
Lima-Serrano, M., González-Méndez, M., Martín-Castaño, C., AlonsoAraujo, I., \& Lima-Rodríguez, J. (2018). Predictive validity and reliability of the Braden Scale for risk assessment of pressure ulcers in an intensive care unit. Medicina Intensiva (English Edition), 42(2), 82-91. https://doi.org/10.1016/j.medine.2018.01.007

Magnan, M. A., \& Maklebust, J. (2009). Braden Scale risk assessments and pressure ulcer prevention planning: What's the connection? Journal of Wound, Ostomy and Continence Nursing, 36(6), 622-634. https://doi.org/10.1097/WON.0b013e3181bd812c

Manzano, F., Navarro, M. J., Roldán, D., Moral, M. A., Leyva, I., Guerrero, C., ... Granada UPP Group (2010). Pressure ulcer incidence and risk factors in ventilated intensive care patients. Journal of Critical Care, 25(3), 469-476. https://doi.org/10.1016/j.jcrc.2009.09.002

Mehta, C., George, J. V., Mehta, Y., \& Wangmo, N. (2015). Pressure ulcer and patient characteristics-A point prevalence study in a tertiary hospital of India based on the European Pressure Ulcer Advisory Panel minimum data set. Journal of Tissue Viability, 3(24), 123-130. https://doi.org/10.1016/j.jtv.2015.04.001

Munro, B. H. (2005). Statistical methods for health care research (5th ed.). Philadelphia, PA: Lippincott Williams \& Wilkins.

National Pressure Ulcer Advisory Panel (2016). NPUAP pressure injury stages/categories. Retrieved from http://www.npuap.org/resources/ educational-and-clinical-resources/npuap-pressure-injury-stages/

National Pressure Ulcer Advisory Panel (2016). Pressure injury prevention points. Retrieved from http://www.npuap.org/wp-content/uploa ds/2016/04/Pressure-Injury-Prevention-Points-2016.pdf

National Pressure Ulcer Advisory Panel (2016). Pressure injury staging illustrations. Retrieved from http://www.npuap.org/resources/ educational-and-clinical-resources/pressure-injury-staging-illus trations/

Nijs, N., Toppets, A., Defloor, T., Bernaerts, K., Milisen, K., \& Van Den Berghe, G. (2009). Incidence and risk factors for pressure ulcers in the intensive care unit. Journal of Clinical Nursing, 18(9), 1258-1266. https://doi.org/10.1111/j.1365-2702.2008.02554.x

Obuchowski, N. A., \& Zhou, X. H. (2002). Prospective studies of diagnostic test accuracy when disease prevalence is low. Biostatistics, 3(4), 477-492. https://doi.org/10.1093/biostatistics/3.4.477

Oğuz, S., \& Olgun, N. (1998). Predicting the pressure sore risk with Braden Scale and determining the effectiveness of predetermined nursing preventing of pressure sore. Journal of Nursing Forum, 3(1), 131-135.

Pancorbo-Hidalgo, P. L., Garcia-Fernandez, F. P., Lopez-Medina, I. M., \& Alvarez-Nieto, C. (2006). Risk assessment scales for pressure ulcer prevention: A systematic review. Journal of Advanced Nursing, 54(1), 94-110. https://doi.org/10.1111/j.1365-2648.2006.03794.x

Seongsook, J., Ihnsook, J., \& Younghee, L. (2004). Validity of pressure ulcer risk assessment scales; Cubbin and Jackson, Braden, and Douglas scale. International Journal of Nursing Studies, 41(2), 199204. https://doi.org/10.1016/S0020-7489(03)00135-4

Serpa, L. F., Santos, V. L. C. D. G., Campanili, T. C. G. F., \& Queiroz, M. (2011). Predictive validity of the Braden Scale for pressure ulcer risk in critical care patients. Revista latino-americana De Enfermagem, 19(1), 50-57. https://doi.org/10.1590/S0104-11692 011000100008

Sousa, B. (2013). Translation, adaptation, and validation of the Sunderland Scale and the Cubbin \& Jackson Revised Scale in Portuguese. Revista Brasileira De Terapia Intensiva, 25(2), 106-114.

Soyer, O. (2014). Sensitivity, specificity, predictive value of Jackson/ Cubbin pressure area risk calculator tool for intensive care unit patients. Master Thesis, Dokuz Eylül University, Izmir/Turkey. (DEU. HSI. MSc-2010970062).

Tubaishat, A., Papanikolaou, P., Anthony, D., \& Habiballah, L. (2018). Pressure ulcers prevalence in the acute care setting: A systematic review, 2000-2015. Clinical Nursing Research, 27(6), 643-659. https:// doi.org/10.1177/1054773817705541 
VanGilder, C., Lachenbruch, C., Algrim-Boyle, C., \& Meyer, S. (2017). The international pressure ulcer prevalence ${ }^{\mathrm{TM}}$ survey: 2006-2015: A 10-year pressure injury prevalence and demographic trend analysis by care setting. Journal of Wound Ostomy \& Continence Nursing, 44(1), 20-28. https://doi.org/10.1097/WON.0000000000000292

Whittington, K. T., \& Briones, R. (2004). National prevalence and incidence study: 6-year sequential acute care data. Advances in Skin \& Wound Care, 17(9), 490-494. https://doi.org/10.1097/00129334200411000-00016

\section{SUPPORTING INFORMATION}

Additional supporting information may be found online in the Supporting Information section at the end of the article.
How to cite this article: Adibelli S, Korkmaz F. Pressure injury risk assessment in intensive care units: Comparison of the reliability and predictive validity of the Braden and Jackson/ Cubbin scales. J Clin Nurs. 2019;28:4595-4605. https://doi. org/10.1111/jocn.15054 